\title{
Férrea pero consciente: disciplina y lazo identitario en las organizaciones clandestinas de las Fuerzas Armadas Revolucionarias de Colombia-Ejército del Pueblo (FARC-EP)
}

\section{Rigid yet Conscious: Discipline and Identitary Bond in the Clandestine Organizations of Revolutionary Army Forces of Colombia-People's Army (FARC-EP)}

\author{
Cristian Acosta Olaya*
}

\begin{abstract}
Resumen: Las FARC-EP suscitaron durante muchos años una fascinación particular en un sinnúmero de académicos, quienes se preguntaron por la permanencia de su lucha armada por más de cinco décadas. Sin embargo, pocos analistas han indagado por el lazo identitario que estableció dicha agrupación al interior de sus filas y su relación con el límite que la guerrilla estableció frente a su alteridad -el establishment colombiano-. El presente trabajo se propone, desde la sociología de las identidades políticas, resaltar las particularidades de la solidaridad interna fariana a partir de algunos de sus propios documentos y normativas disciplinarias. De esta manera, buscaremos indagar sobre la tensión interna de las FARC y de sus organizaciones clandestinas entre una vertical e incuestionable jerarquía militar y sus distintos objetivos políticos.
\end{abstract}

Palabras clave: Identidades políticas, organizaciones revolucionarias, FARC-EP, violencia política, clandestinidad.

\begin{abstract}
For many years, FARC - EP stirred up a singular fascination among countless scholars who wondered about the more than five - decade - long duration of their armed struggle. However, very few analysts have inquired about their identity bond, stablished by said group inside its ranks and the relationship this guerrilla had set in regards to its otherness -the colombian stablishment-. This paper intends to highlight the particularities of the inner farian solidarity, from the sociology of political identities, parting from some of their own documents and disciplinary regulations. Therefore, we will try to inquire about - FARC and its clandestine organizations' inner tension between a vertical and unquestionable military hierarchy and its different political goals.
\end{abstract}

Keywords: Political Identities, Revolutionary Organizations, FARC-EP, Political Violence, Clandestinity.

Recibido: 27 diciembre 2018 Aceptado: 18 marzo 2019

\footnotetext{
* Colombiano. Candidato a Doctor en Ciencias Sociales en la Universidad de Buenos Aires. La redacción de este trabajo ha sido posible gracias a una beca doctoral del CONICET, Argentina. cjacostao@gmail.com - Agradezco la lectura de versiones preliminares de este texto a Andrés Manosalva, Diego Paredes y David Santos. Los errores en los que pueda incurrir este trabajo son, por supuesto, de mi absoluta responsabilidad.
} 


\section{Introducción}

El conflicto armado colombiano es, sin duda, uno de los temas que mayor interés ha generado al interior de las ciencias sociales latinoamericanas y norteamericanas ${ }^{1}$, esto debido tanto a su larga permanencia -desde mediados de siglo XX hasta nuestros días- como a la multiplicidad de los actores que se han visto involucrados en el mismo: ejércitos regulares, fuerzas paramilitares y, especialmente, agrupaciones guerrilleras. Sobre estas últimas, el Ejército de Liberación Nacional (ELN) y las Fuerzas Armadas Revolucionarias de Colombia-Ejército del Pueblo (FARC-EP) despertaron la curiosidad de diversos analistas que se preguntan todavía por su sinuosa y prolongada existencia ${ }^{2}$.

Es cierto que las lógicas políticas y tácticas militares de ambas organizaciones han mutado radicalmente durante el último lustro; por una parte, las FARC han emprendido el largo y espinoso camino de hacer política sin armas bajo las prerrogativas de los Acuerdos de Paz firmados en La Habana con el gobierno colombiano y ratificados en las postrimerías del segundo periodo presidencial de Juan Manuel Santos (2010-2018)3; por otra parte, y como consecuencia del fracaso en la construcción de una agenda de diálogo con el gobierno de Santos, el futuro del ELN como organización político-militar parece no ser otro que el de continuar librando esporádicas luchas contra el Ejército colombiano sin perspectiva alguna -a corto plazo- de llegar a un acuerdo de cese de hostilidades con el actual gobierno de Iván Duquet.

Ahora bien, en lo que refiere puntualmente a las FARC, las preocupaciones más recientes de académicos, ONGs y analistas de distintos enfoques han gravitado en elaborar medidas institucionales y sugerir reformas jurídicas en aras de evitar que los combatientes rasos desmovilizados y sus antiguos mandos regresen a las armas, integrándolos definitivamente a la vida civil, sin embargo, el objetivo de este trabajo no es el de contribuir en aquellas inquietudes -completamente necesarias, valga decirse-

${ }^{1}$ La bibliografía existente sobre el conflicto armado en Colombia es extensísima. Nos parece importante, sin embargo, remitir al lector la clásica obra sobre la Violencia de mediados de siglo XX de German Guzmán Campos, Orlando Fals Borda y Eduardo Umaña Luna, La violencia en Colombia: estudio de un proceso social, Bogotá, Ediciones Tercer Mundo, 1962. Para una lectura que abarca otros períodos también de la centuria pasada, ver las siguientes obras: Gonzalo Sánchez y Ricardo Peñaranda (comp.), Pasado y presente de la Violencia en Colombia, Bogotá, Fondo Editorial CEREC, 1986; Daniel Pécaut, Orden y violencia: evolución socio-política de Colombia entre 1930 y 1953, Bogotá, Editorial Norma, 200 1; Paul Oquist, Violencia, conflicto y politica en Colombia, Bogotá, Instituto de estudios colombianos-Biblioteca Banco Popular, 1978.

2 Describir con precisión la trayectoria de las múltiples organizaciones guerrilleras que surgieron en Colombia desde los años sesenta hasta el presente excede por mucho el espacio y la pretensión analítica de este trabajo. Sin embargo, resulta importante contextualizar las etapas en las que dichas organizaciones surgieron. Ciertamente, como lo sintetiza el analista colombiano Jorge Giraldo Ramírez, en América Latina existieron tres "olas guerrilleras" en la segunda mitad del siglo XX: la primera ola, inspirada en la Revolución Cubana, atestiguó la creación de organizaciones político-militares de izquierda que tenían como epicentro las zonas rurales durante gran parte de los años sesenta; en la segunda ola, el modelo de la agrupación uruguaya Movimiento de Liberación Nacional-Tupamaros influyó en el surgimiento de diversas guerrillas urbanas latinoamericanas, esto en el decenio de 1970; finalmente, la tercera ola tiene como inspiración la victoria sandinista en Nicaragua, lo que generó la réplica de su estratégica político-militar - entre 1979 y algunos años previos a la caída del Muro de Berlín- por parte de muchas organizaciones revolucionarias del subcontinente. En lo que respecta a Colombia, a mediados de los años ochenta existían guerrillas de relevancia nacional como el Movimiento Revolucionario 19 de abril (M-19), el Ejército Popular de Liberación (EPL) y el Movimiento Indígena Quintín Lame, entre otras. Sin embargo, las organizaciones que sobrevivieron a todas las "olas" descritas por Giraldo Ramírez fueron principalmente las FARC y el ELN. Jorge Giraldo Ramírez, Las ideas de la guerra. Justificación y crítica en la Colombia contemporánea, Bogotá, Debate, 2015, 40-62.

${ }_{3}^{3}$ Desde 2017 las FARC cambió su nombre por Fuerza Alternativa Revolucionaria del Común -conservando su sigla distintiva-, constituyéndose en un movimiento político con aspiraciones electorales a mediano y largo plazo.

${ }^{4}$ El ELN no ha logrado concretar una mesa de diálogo político con el actual presidente de Colombia, Iván Duque. Integrante del movimiento político del ex presidente Álvaro Uribe, quien en sus dos periodos presidenciales (2002-2010) exacerbó el discurso anti insurgente en Colombia, Duque se niega a negociar con el ELN hasta que esta organización guerrillera detenga sus acciones militares. 
abocadas a la construcción de un escenario de "posconflicto" en Colombia5. En cambio, mirando hacia el pasado, lo que buscaremos en el presente texto es indagar sobre algunos fenómenos propios de las FARC como organización guerrillera activa en Colombia'; así, pretendemos analizar a esta agrupación en tanto organización político militar enfrentada al establishment colombiano auscultando, puntualmente, la construcción del lazo identitario al interior de sus filas guerrilleras y de sus organizaciones políticas subsidiarias.

En este orden de ideas, analizaremos el Estatuto, Reglamento y Normas de las milicias bolivarianas de mayo 1989, textos normativos en los cuales se establecen ciertos patrones de comportamiento interno de las organizaciones clandestinas conducidas por las FARC: el Movimiento Bolivariano (MB) y el Partido Comunista Clandestino Colombiano (PCCC o PC3); en este sentido, haremos también referencia al documento Principios de trabajo clandestino difundido por la organización fariana entre 1999 y 2001. Consideramos que estos textos son relevantes en tanto reflejan la construcción de una identidad guerrillera a partir del rol cardinal que las FARC le dan a la disciplina interna. Ciertamente, estos documentos contienen objetivos, tareas, justificaciones de la lucha armada, entre otros elementos, los cuales permiten reconstruir algunos de los rasgos solidarios más importantes de dicha agrupación revolucionaria en su accionar militar y político contra el Estado colombiano. Esto nos permitirá, finalmente, plantear -a manera de hipótesis- un vínculo entre la exacerbación de la disciplina interna y la construcción de un enemigo irredimible, cuyo único procesamiento posible es a través de su eliminación física.

\section{Las identidades revolucionarias. Las FARC y sus etapas}

En una sugestiva propuesta tipológica, el sociólogo argentino Gerardo Aboy Carlés considera a las identidades políticas populares como una serie de solidaridades que se constituyen cuando una "parte" de la sociedad (plebs), al sentirse negativamente privilegiada respecto al "todo comunitario" (populus), establece una imprecación particular al orden existente. Efectivamente, este tipo de identidad política ${ }^{7}$ se distinguiría no necesariamente por su pertenencia a un sector del sistema de producción (por ejemplo, "los sectores subalternos", "los pobres", "los desposeídos", etc.) sino por la forma en que establecen y procesan a su alteridad, esto es, a partir de lo que Aboy Carlés denomina como el "principio de escisión"8. Así pues, para el autor existen tres tipos de identidades populares: las identidades totales, donde la plebs busca su expansión solidaria casi siempre de manera violenta e intransigente a toda la comunidad para convertirla a su imagen (las luchas anticoloniales inspiradas en Frantz Fanon, por caso); las identidades parciales, como contracara de las totales, no pretenden el copamiento de sus rasgos

${ }^{5}$ Entre muchos libros que surgieron sobre la temática del posconflicto, remitimos al lector las siguientes obras: Angelika Rettberg (comp.), Construcción de paz en Colombia, Bogotá, Ediciones Uniandes, 2013; Claudia López Hernández, ;Adiós a las FARC! ¿ Y abora qué?, Bogotá, Penguin Random House, 2016.

${ }^{6}$ En esto queremos ser enfáticos: las raíces del conflicto armado colombiano y el rol de estas agrupaciones en el mismo no hacen parte del objetivo del presente trabajo; tampoco lo es discutir sobre las causas del enfrentamiento entre grupos alzados en armas - de diferente signo político- y el Estado colombiano. De nuevo, remitimos al lector la bibliografía sobre el conflicto armado citada anteriormente.

7 Aboy Carlés define a las identidades políticas como "el conjunto de prácticas sedimentadas, configuradoras de sentido, que establecen a través de un mismo proceso de diferenciación externa y de homogeneización interna, solidaridades estables, capaces de definir, a través de unidades de nominación, orientaciones gregarias de la acción en relación a la definición de asuntos públicos. Toda identidad política se constituye y transforma en el marco de la doble dimensión de una competencia entre las alteridades que componen el sistema y de la tensión con la tradición de la propia unidad de referencia". Gerardo Aboy Carlés, Las dos fronteras de la democracia argentina: la reformulación de las identidades políticas de Alfonsín a Menem, Rosario, Homo Sapiens, 54. Para este autor, toda identidad política precisa de tres elementos para su conformación: la construcción de una alteridad, una dimensión representativa y la formulación de su propia tradición.

8 Gerardo Aboy Carlés, "De lo popular a lo populista o el incierto devenir de la plebs", Gerardo Aboy Carlés, Sebastián Barros y Julián Melo (coord.), Las brechas del pueblo. Reflexiones sobre identidades populares y populismo, Los Polvorines, UNDAV Ediciones, 2013, 21-24. 
identitarios a todo el populus sino que procuran coexistir -aunque de manera endogámica- con las otras identidades sin detrimento de la puesta en cuestión del orden existente (por ejemplo, las Panteras Negras en Estados Unidos); y finalmente, las identidades con pretensión hegemónica, muy recurrentes en la democracia liberal, emergen cuando la plebs busca la transformación progresiva del populus a su solidaridad, por lo cual este tipo de identidades - a diferencia de las dos anteriores- establecen fronteras porosas frente a su alteridad y reniegan de cualquier tipo de segregación propia (pensemos en los partidos socialdemócratas europeos, preocupados por el mantenimiento y extensión de su electorado) ${ }^{9}$.

En nuestro caso, las Fuerzas Armadas Revolucionarias de Colombia -como organización guerrillerason un caso de identidades totales debido a su pretensión de transformar y expandir su solidaridad al todo comunitario por medio de la eliminación física de sus adversarios. Como es sabido, estos rasgos son propios de muchas organizaciones armadas de izquierda que surgieron entre los años sesenta y setenta del siglo XX en América Latina. En efecto, como lo resaltan Daniela Slipak y Sebastián Giménez, la característica definitoria de las "identidades revolucionarias" es la ausencia de porosidad en el límite solidario que estas establecen frente a sus adversarios; en otras palabras, las organizaciones revolucionarias tendieron a realizar un trazado infranqueable de su frontera identitaria, rigidizando la barrera establecida entre un "nosotros" y un "ellos". Con esto, es cierto, se impedía la conversión -o "regeneración"- del enemigo al campo solidario propio; por consiguiente, esta forma particular de construir un pueblo generalmente implicó una exacerbación violenta e irreversible de la eliminación física hacia su otredad ${ }^{10}$.

$\mathrm{Al}$ respecto, Claudia Hilb considera que el uso de la violencia política, tan peculiar de las organizaciones guerrilleras -como fue el caso de Montoneros en Argentina durante la década de 197011 pero también el de las FARC desde 1964 hasta la segunda década del siglo XXI-, traía consigo un renunciamiento de lo que con Aboy Carlés denominábamos la "pretensión hegemónica" del actuar político. En palabras de la autora argentina:

La tesis de la vanguardia política de cuño leninista es reformulada por los grupos guerrilleros en términos de vanguardia armada; y si ya la tesis originaria de la vanguardia aspiraba a poder prescindir de una legitimación mayoritaria expresa, su reinscripción en términos de vanguardia armada permite resolver la cuestión de la hegemonía política suplantándola por la lógica del enfrentamiento de aparatos militares $^{12}$.

Por otra parte, el establecimiento de una frontera identitaria infranqueable contra el adversario y la renuncia a una construcción hegemónica de la política ${ }^{13}$, son factores resaltados también -en sus propios términos- por Eduardo Pizarro Leongómez en sus indagaciones sobre las guerrillas

\footnotetext{
9 Ibid., 24-35.

10 Daniela Slipak y Sebastián Giménez, "Pueblo, revolución y violencia. Las reactualizaciones revolucionarias del populismo", Estudios Politicos 43, México D.F., enero-abril 2018, 104-105. Reiteramos que, en consonancia con lo propuesto por Aboy Carlés, todas las identidades políticas se configuran estableciendo una alteridad que toman como referencia; sin embargo, es el procesamiento que se le da a su otredad lo que hace posible discriminar distintos tipos de solidaridades políticas.

11 Sobre la construcción identitaria de Montoneros, ver el excelente trabajo de Daniela Slipak, Las revistas montoneras, Buenos Aires, Siglo XXI, 2015.

12 Claudia Hilb, Usos del pasado. Qué hacemos hoy con los setenta, Buenos Aires, Siglo XXI, 2013, 27-28.

$13 \mathrm{Si}$ bien la referencia a la construcción hegemónica de la política ha tenido una impronta netamente gramsciana dentro de la tradición marxista, en este trabajo tomamos las disquisiciones al respecto de Ernesto Laclau y Chantal Mouffe; según estos autores, la Hegemonía es un tipo de relación política -o conformación de identidades políticas- que supone la articulación equivalencial y progresiva de demandas sociales que se anudan en oposición a un lugar que las desconoce; dicha progresividad sucede gracias a la puesta en cuestión de los límites de la propia identidad, lo que le permite la asimilación de su alteridad al propio campo solidario o -dicho en términos teológicos- "la conversión de los adversarios a la nueva fe". Ernesto Laclau y Chantal Mouffe, Hegemonía y estrategia socialista, Buenos Aires, FCE, 182-183, y Aboy Carlés, op. cit. (2013), 34.
} 
colombianas ${ }^{14}$. Para este autor, las organizaciones guerrilleras pueden ser de tres tipos: por una parte, existen guerrillas de tipo societal, cuya característica principal es representar a un sector social determinado, es decir, un "movimiento social armado" en tanto prolongación bélica de un actor organizado. En contraposición a la anterior, la guerrilla militar reduce su razón de ser a la maquinaria de guerra, con lo que no busca su prolongación política en la población, sino que se agota en ser un mero aparato armado. Por último, la guerrilla de partido es una organización armada subordinada a un proyecto político y que, en términos de Pizarro Leongómez, vendría a ser el intermedio que supera la topología meramente societal y que no se reduce a la organización militar; por ende, según este autor colombiano, una guerrilla que alcanza su mayor capacidad de poder es la que logra abarcar simultáneamente estos tres rasgos (societal, militar, político) ${ }^{15}$.

En lo que respecta al devenir de las FARC, el investigador Mario Aguilera considera que existen cuatro momentos en la trayectoria de esta guerrilla: el primero abarca los años 1949-1978, años en los cuales se configura un movimiento guerrillero comunista en las zonas rurales del país a partir de grupos de autodefensas campesinas que surgieron en el periodo de la Violencia (1946-1953) ${ }^{16}$, dando origen a las FARC a mediados de los años sesenta. Un segundo periodo inicia en 1978 y culmina en 1991, en el que surgen, dentro del contexto de la Séptima Conferencia de la organización, dos directrices cardinales para su accionar posterior: por una parte, se adopta la sigla "Ejército del Pueblo" (EP) -giro de lo defensivo hacia lo ofensivo, adoptando la estrategia de "guerra popular prolongada"- y, por otra parte, se crea el "Plan Estratégico" para la toma del poder, el cual plantea la toma de la capital del país (Bogotá) como objetivo principal de las acciones armadas; estos objetivos estaban inspirados en la coyuntura insurreccional de Nicaragua y de El Salvador. El tercer momento de las FARC (1991-2008) comprende el surgimiento de un "ideario bolivariano" (el PCCC y MB antes mencionados); los fracasados diálogos de paz con el gobierno de Andrés Pastrana entre 1999 y 2001, impulsarían la apabullante victoria de Álvaro Uribe bajo la promesa de acabar militarmente con la insurgencia del país. Finalmente, el cuarto y último periodo de este grupo guerrillero, según Aguilera, va desde la muerte de su máximo líder histórico, Pedro Antonio Marín (alias 'Tirofijo') en marzo de 2008 hasta las negociaciones de paz con el gobierno de Santos, todo esto en un contexto de una inusitada degradación del conflicto armado, especialmente por los vínculos entre actores armados y el narcotráfico ${ }^{17}$.

\footnotetext{
${ }^{14} \mathrm{El}$ académico francés Daniel Pécaut afirma que en entre los años sesenta y setenta del siglo XX en Colombia se conforman una serie de guerrillas " [...] que en las décadas siguientes confieren a la lucha armada un rol central; las FARC, fieles al Partido Comunista ortodoxo; el ELN que se reclama del guevarismo; el EPL [Ejército Popular de Liberación] que reivindica tesis maoístas. Un poco más tarde, después de las elecciones de 1970, el M-19 aparece con un rechazo del dogmatismo y un llamado sobre todo a un nacionalismo bolivariano": Daniel Pécaut, "Una lucha armada al servicio del statu quo social y político", Informe para la Comisión Histórica del Conflicto y sus Víctimas, La Habana, 2015, 24. La versión digital de este documento se puede encontrar en: https://www.ambitojuridico.com/BancoMedios/Documentos\%20PDF/una-lucha-armada-al-serviciodel-statu-quo-social-y-politico-1447170837-1460380657.pdf [Revisado el 10 de diciembre de 2018]

15 Eduardo Pizarro Leongómez, Insurgencia sin revolución. La guerrilla en Colombia en una perspectiva comparada, Bogotá, Tercer Mundo-IEPRI, 1996, 57-58.

${ }^{16}$ Como se ha establecido en los estudios abocados a la historia colombiana, se habla de la Violencia (con mayúscula) para referirnos al enfrentamiento bélico entre militantes de los dos partidos tradicionales -conservadores y liberales de mediados de siglo XX; en cambio, y para efectos de este trabajo, por violencia (en minúscula) nos referimos, básicamente, al recurso de eliminación física del adversario político y propio de las identidades revolucionarias.

17 Mario Aguilera, Guerrilla y población civil. Trayectoria de las FARC 1949-2013, Bogotá, Centro Nacional de Memoria Histórica, 2014, 337-340. Por su parte, para Carlos Medina Gallego la dinámica de las FARC fue la de oscilar entre la contracción y el crecimiento - "flujos y reflujos"- en su influencia política y militar. Para este autor, la historia de la guerrilla fariana se divide en tres periodos: el primero se da en el paso de autodefensas campesinas entre las décadas de 1950 y 1960 a guerrillas móviles en los años setenta adoptando la estrategia -en relación con el Partido Comunista (PCC)- de "la combinación de todas las formas de lucha". El segundo periodo comprende las fracasadas negociaciones de paz con el gobierno colombiano de 1984, el asesinato sistemático por parte de fuerzas del Estado y paramilitares de miembros de la Unión Patriótica (UP) -coalición política entre el PCC y las FARC- y su crecimiento militar a fines del siglo XX gracias al control geográfico de la zona del Caguán, al sur de Colombia. El tercer y último periodo de la historia fariana se inicia con el gobierno de Álvaro Uribe en 2002
} 
En este orden de ideas, es posible afirmar que en su larga etapa de surgimiento y consolidación las FARC fueron una guerrilla de partido en tanto pretendieron constituirse como el "brazo armado" del Partido Comunista Colombiano (PCC). Por su puesto, sin obviar los elementos societales y militares de la agrupación, su calidad de agrupación insurreccional suponía que la adhesión a la misma se realizaba a través de la difusión ideológica, con una vanguardia política partidista consolidada y estableciendo la enemistad total contra el establishment colombiano ${ }^{18}$. Sin embargo, con su paso de una guerrilla móvil a un ejército regular ("Ejército del Pueblo") en 1982, los vínculos societales de las FARC en sus epicentros de acción se fueron deteriorando y con ello también su relación con la estructura política del Partido Comunista. En otros términos, si las FARC - en tanto fenómeno partisano ${ }^{19}$-: mantuvieron su carácter irregular y aumentaron su movilidad militar para la lucha armada, la pérdida del vínculo societal conllevaría a la precarización del compromiso (engagement) político vital para su funcionamiento.

\section{Entre lo militar y lo político. Las FARC y sus milicias}

Las FARC estuvieron al tanto de su problemática construcción política en el país, por lo cual desde fines de la década de 1990 implementaron una serie de transformaciones organizativas. Por una parte, se realizaría una reformulación de la imaginería fariana, cuya transformación giró en retomar la figura de Simón Bolívar en detrimento de la iconografía del marxismo-leninismo ${ }^{20}$. Por otra parte, y en relación con lo anterior, esta guerrilla crearía una nueva estrategia ofensiva que implicaba no solo su fortalecimiento militar en las zonas rurales sino también la creación de organismos políticos subsidiaros y clandestinos cuyo centro de acción se daría fundamentalmente en los principales centros urbanos de Colombia. Dichos organismos fueron el Partido Comunista Clandestino Colombiano y el Movimiento Bolivariano.

Es innegable que la Séptima Conferencia Nacional de mayo de 1982 supuso una transformación inédita de las FARC desde su fundación a mediados de la década de $1960^{21}$. En dicho año, esta agrupación político-militar estableció una estructura basada en la verticalidad de mando acorde a su pretensión de ser el "Ejército del Pueblo" -se agrega "EP" a su sigla-, lo que en otras palabras significaba una modernización definitiva de su estructura bélica. Esto dio como resultado la

\footnotetext{
y llega hasta la administración del Presidente Santos: Carlos Medina Gallego, FARC-EP: Flujos y reflujos. La guerra en las regiones, Bogotá, Universidad Nacional de Colombia-UNIJUS, 2011, 295.

18 Pizarro Leongómez, op. cit., 59.

19 Para el jurista alemán Carl Schmitt existen cuatro criterios para entender el actuar guerrillero o partisano: irregularidad, movilidad acentuada, intensidad del engagement político y el carácter telúrico: Carl Schmitt, Teoría del partisano. Acotación al concepto de lo político, Buenos Aires, Struhardt \& Cía., 2005, 30 y 148.

20 Esta torsión iconográfica, sin embargo, no fue exclusiva de las FARC. Otras organizaciones, especialmente las guerrillas urbanas de los años setenta, empezaron a utilizar "un lenguaje y una simbología que los conectaba con la tradición de la independencia nacional: los uruguayos con [...] Túpac Amaru II, nombre genérico usado por los españoles para denominar a los rebeldes; los argentinos, con los levantamientos de comienzos del siglo XX [las montoneras]; los colombianos, con Simón Bolívar": Giraldo Ramírez, op. cit., 50; de hecho, uno de los golpes mediáticos más emblemáticos del M-19 fue el robo de la espada de Bolívar en enero de 1974. Asimismo, una fugaz alianza política y militar entre distintas organizaciones guerrilleras que tuvo lugar entre 1987 y 1990 fue bautizada como Coordinadora Guerrillera Simón Bolívar (CGSB). Es importante agregar, por último, que el "bolivarianismo" que surgirá con la asunción de Hugo Chávez a la presidencia venezolana en 1998 reafirmaba la torsión simbólica implementada por la agrupación fariana.

${ }^{21}$ En el portal web de las FARC-EP se puede leer todavía en respuesta al interrogante "¿Qué es la Conferencia Nacional de Guerrilleros?" lo siguiente: "La Conferencia, es decir, el Congreso de las FARC-EP se ejercita la Democracia Revolucionaria, la Democracia Proletaria, no la Democracia de la pequeña burguesía revolucionaria, sino la Democracia de los Proletarios revolucionarios, que conforman hoy lo que nosotros somos. En la Conferencia se plantea [...] qué es lo que vamos a hacer, cómo adelantamos el proceso revolucionario, cómo va a ser la confrontación de orden militar y también necesariamente de orden político": ver: FARC-EP: Octava Conferencia Guerrillera, 1993. En línea http://www.farc-ep.co/octava-conferencia/quees-la-conferencia-nacional-de-guerrilleros.html [revisado el 10 de diciembre de 2018].
} 
consolidación de una jerarquía bastante radical de mando, estableciendo como cabeza de la organización al Estado Mayor Central y al Secretariado del Estado Mayor Central22. Igualmente, en la mencionada Conferencia Guerrillera se ratificaron y difundieron tanto las "Normas Internas de Comando", estipulaciones que regulaban la vida de los guerrilleros y de sus respectivos campamentos, como también el "Reglamento de Régimen disciplinario" para cumplimiento de todos los estratos jerárquicos. Al respecto, Mario Aguilera enfatiza que la normas de las FARC -vigentes hasta su desmovilización en noviembre de 2016-:

[...] cumplen con la función de regular la vida cotidiana de la organización con firmeza y severidad. Este rasgo diferencia a las FARC de otras organizaciones guerrilleras cuyas normas se aplican o aplicaban con mayor flexibilidad, lo cual a veces impide cumplir las metas que se proponen: el M-19 por ejemplo, no se caracterizó precisamente por su rigidez en las aplicaciones normativas ${ }^{23}$

La normatividad interior iba a compás del rol regulador de las relaciones sociales que asumieron las FARC durante varias décadas en territorios marginados de la geografía colombiana. Por una parte, hacia el exterior de sus filas, las FARC habían pretendido imponer el monopolio de la fuerza en muchas zonas rurales donde el Estado colombiano estaba ausente: el castigo a ladrones, violadores sexuales, entre otras medidas, fueron aceptadas en un comienzo por las comunidades donde la presencia de la policía era limitada. Estos "ajusticiamientos", al decir de Aguilera, fueron generando progresivamente malestar en la sociedad civil, especialmente cuando los juicios "revolucionarios" eran infundados y se hicieron reiteradas las ejecuciones a presuntos delincuentes ${ }^{24}$. Por otra parte, y más importante para los fines de este trabajo, hacia el interior de sus filas la normatividad interna de las FARC sirvió como un entramado de reglas que definió conductas censurables - divididas en "faltas y delitos"-, estableció las formas de realizar juicios, los derechos de los procesados y las sanciones que ameritaba cada conducta reprobable dentro de la organización.

Como era de esperarse, la preocupación respecto a la posibilidad de tener infiltrados o colaboradores del Estado colombiano al interior de la organización se volvería un tema central para el accionar militar y de justicia fariano. Aunque en dichas Normativas de las FARC no se consigne explícitamente que la ejecución de sus propios integrantes era un recurso válido para castigar la delación, este método fue varias veces reconocido como método para depurar las filas de la agrupación. En una entrevista originalmente publicada en 1984, alias Jacobo Arenas -uno de los fundadores y personajes emblemáticos de las FARC- afirmaba que la "sanción máxima" de la guerrilla "es el fusilamiento pero para delitos como la deserción consciente, el ponerse al servicio del enemigo" 25 . Frente a lo anterior, una disidencia de las FARC conocida como el Frente "Ricardo Franco" brindaría algunas pistas de cómo el enfrentamiento armado había generado una paranoia colectiva en la comandancia guerrillera. Si bien es cierto que en el año de 1982 el dirigente del Frente "Ricardo Franco", alias Javier Delgado, había sido expulsado de las FARC por malversación de recursos y por el uso excesivo de torturas y ejecuciones para resolver las tensiones internas de su tropa, Delgado posteriormente formó su propio Frente disidente argumentando que el Estado Mayor de las FARC traicionaba los postulados de la Séptima conferencia. Pero el hecho más conocido del Frente "Ricardo Franco" sería la ejecución de 164 de sus hombres entre noviembre de 1985 y enero de 1986, acusados por el mismo Javier Delgado

\footnotetext{
22 Medina Gallego, op. cit., 56-57.

23 Aguilera, op. cit., 83 - el resaltado es nuestro. Recordemos que la organización Movimiento 19 de abril (M-19) surgió en la primera mitad de la década de 1970 como una organización de guerrilla urbana inspirada, básicamente, en los Tupamaros uruguayos.

24 Aguilera relata que, incluso, las primeras escisiones internas de las FARC data de 1978, y se dan justamente por ejecuciones arbitrarias por parte de los altos mandos que controlaban parte del Urabá antioqueño: Ibid., 103.

${ }_{25}$ Carlos Arango, FARC veinte años: de Marquetalia a La Uribe, Bogotá, Ediciones la Aurora, 47.
} 
de ser infiltrados de las fuerzas del Estado o miembros la inteligencia estadounidense; estos hechos fueron conocidos posteriormente como la "masacre de Tacueyó" (corregimiento ubicado en el departamento del Cauca, suroccidente del país) ${ }^{26}$.

De cualquier manera, como lo resalta el investigador Santos Alonso Beltrán, la mencionada Séptima Conferencia fue el hito clave que estableció para las FARC el credo en la disciplina militar. Como ya se mencionó, desde 1982 la organización fariana buscó configurarse como grupo bélico moderno implementando jerarquías, rutinas y dispositivos militares y como un partido en armas gracias a sus conexiones con el Partido Comunista Colombiano. Sin embargo, la separación definitiva con el PCC -por divergencias ideológicas que surgieron tras a la caída del Muro de Berlín- obligaría a que las FARC construyeran sus propias organizaciones o plataformas políticas, el PCCC y el MB, orientadas a la consolidación política y al crecimiento militar de la guerrilla ${ }^{27}$.

En este sentido, a lo largo de la década de 1980 y del decenio siguiente, la organización de las FARC tendría dos componentes principales: en primer lugar, la guerrilla entendida cabalmente como la agrupación de "revolucionarios profesionales", "combatientes internos que tienen una conexión menor con la población civil, más nomádicos, algunas veces concentrados en los campamentos y con una orientación mucho más militar"; y, en segundo lugar, las milicias, compuestas por combatientes dentro de la población civil, "asentados en el territorio de presencia del actor armado [que] siguen una vida cotidiana [;] además cumplen tareas militares de inteligencia, encuadramiento militar de la población y hostigamiento ligero a unidades militares enemigas"28. En términos de Beltrán:

La diferencia fundamental entre el guerrillero interno y el miliciano estriba en la permanencia del miliciano dentro de la población, su menor entrenamiento militar, su papel de tropa ligera y de ocupación, la posibilidad de seguir desarrollando una vida cotidiana y de que sólo en ocasiones particulares (entrenamiento, adoctrinamiento político, preparación y cumplimiento de misiones o preparación previa a un posible enfrentamiento) sea "acuartelado" [reclutado como soldado guerrillero] [...] Las Milicias responden a los mandos de Frente ${ }^{29}$.

En síntesis, con la normativa que surgió de las Conferencias Guerrilleras de fines de los setenta y principios de los ochenta, las FARC buscaron establecer una disciplina incuestionable vinculada a un ordenamiento puramente vertical. Ahora bien, creemos pertinente preguntarnos: ¿cuál es el papel que juegan la exacerbación de la verticalidad, la jerarquía estrictamente militar y la disciplina interna en la forma de cohesionar internamente a la organización? ¿Podríamos afirmar la existencia de algún vínculo entre dichos elementos de la organización fariana y la enemistad absoluta que planeaba la agrupación alzada en armas contra el establishment colombiano?

\section{La disciplina "férrea pero consciente": Estatuto de las milicias bolivarianas y Principio de trabajo clandestino}

El Estatuto de las milicias bolivarianas ${ }^{30}$ data de 1989, momento de total distanciamiento de las FARC con las negociaciones de paz que el gobierno de Virgilio Barco (1986-1990) había emprendido con distintos

\footnotetext{
26 Aguilera, op. cit., 121. Más adelante volveremos a hacer referencia a la tragedia de Tacueyó.

27 Santos Alonso Beltrán, "FARC-EP: una reflexión sobre su organización política y militar", Carlos Medina Gallego (Coord.), FARC-EP. Temas y problemas nacionales, 1958-2008, Universidad Nacional-UNIJUS, 2008, 73.

28 Ibid., 78.

${ }^{29}$ Idem.

30 Recordemos que en este documento están incluidos el Estatuto y el Reglamento de las milicias, así como también las Normas generales internas de comando.
} 
grupos armados, especialmente con el M-19. El Estatuto parte de considerarse como pieza vital del "Plan Estratégico" de las FARC-EP, es decir, el método trazado para la toma definitiva del poder en menos de una década. Divido en cinco breves capítulos, dicho documento considera a las milicias como un espacio político y militar en el que pueden ingresar "todas las personas cuya integridad física e intereses sean amenazados por la represión reaccionaria, la guerra sucia y sus funestas secuelas" 31 . Después de explicar la organización militar a partir del número de milicianos y de su clara subordinación a los comandantes de los Frentes guerrilleros, se estipulan los "requisitos" para ser miembro de la organización: ser recomendado por alguien de confianza, ser persona "normal" y "honesta", tener entre 16 y 30 años, sostener una posición "clara" de defensa de los intereses populares, no ser traficante o consumidor de drogas y no ser informante "del enemigo" ni tampoco una persona "inmoral" 32 .

Asimismo, en el capítulo IV de este Estatuto se afirma que para asegurar la unidad de los milicianos, es indispensable la implementación de "normas disciplinarias" obligatorias, sujetas estas a sanciones. Se puede leer en el documento lo siguiente:

[L]a disciplina de las milicias es férrea pero consciente y están obligados a acatarla sin reticencia todos los integrantes del movimiento de las milicias tanto en escala veredal, regional, y nacional partiendo de que las milicias bolivarianas son parte integrante y fuerza de esencial significación del movimiento revolucionario [...]"33.

En el Estatuto se consideran como faltas "graves" el robo, el tráfico de drogas, la extorsión, la calumnia y "la inmoralidad", por lo que las sanciones van desde la "crítica pública y autocrítica" hasta la "expulsión del movimiento de milicias" 34.

De manera similar al Estatuto, el Reglamento de las milicias hace hincapié en que es importante implementar la "disciplina política" y en la necesidad de establecer una disciplina militar que sea "proletaria, férrea pero consciente" 35 . Pese a ser muy similar al Estatuto, la particularidad del Reglamento miliciano no es sólo su particular exacerbación de la obediencia incuestionable a los mandos superiores ${ }^{36}$ sino también la exaltación del valor de la "reserva" del miliciano, es decir, el mantenimiento en secreto de la información para sostener la organización clandestina. En esta reglamentación, ciertamente, se estipulan sanciones de tipo militar, como hacer guardia -o "patio"- en horarios nocturnos, realizar trabajos prácticos individuales o grupales, el "acuartelamiento" y los llamados a la "autocrítica". Por último, las Normas generales internas de comando remiten al ordenamiento específicamente militar, estando ausente cualquier referencia a objetivos políticos de la guerrilla.

Por su parte, en los Principios de trabajo clandestino ${ }^{37}$ se mencionan los tres fundamentos para el correcto funcionamiento de las organizaciones secretas y de inteligencia revolucionarias: "la clandestinidad, la compartimentación y la verticalidad"38.

31 FARC-EP, Estatuto, reglamento y normas de las milicias bolivarianas, 1989, 1.

32 Ibid., 2.

33 Idem. - el resaltado es nuestro.

34 Ibid., 3. En contraste a la "expulsión" de las milicias se puede encontrar la postura de las FARC sobre el reclutamiento indeterminado en las guerrillas. Según un comunicado citado por Santos Alonso, la organización fariana afirmaba que "[a] filas se llega por tiempo indefinido. Los combatientes de las FARC-EP son profesionales revolucionarios hasta el triunfo de la revolución.”: Beltrán, op. cit., 78 - el resaltado es nuestro.

35 FARC-EP, op. cit., 4.

36 Estas milicias "están bajo la dirección inmediata de los Estados Mayores de los Frentes de las FARC, del Estado Mayor Central, de los Plenos del Estado Mayor y de las Conferencias Nacionales de las FARC-EP”: Beltrán, op. cit., 78.

${ }^{37} \mathrm{El}$ documento carece de fecha pero que se presume que empezó a ser difundido entre 1999 y 2001. 
En primer lugar, la clandestinidad es descrita como un valor que tiene como base "el secreto", no sólo como protección hacia fuera sino también a nivel interno de la organización. En consecuencia, el miliciano debe mimetizarse con su entorno y pasar desapercibido, sin atraer la atención o caer en el vicio del "clandestinaje", esto es, caer en una "apatía sospechosa". Al igual que en parte del Estatuto remitido anteriormente, en los Principios de trabajo... se insiste en la importancia de la "reserva" para el trabajo clandestino, pero en este documento se hace una mención explícita de la dimensión afectiva y de la vida privada del miliciano:

La Fuerza del Revolucionario reside en gran parte, en su capacidad de reserva. Se trata de una necesidad. El afecto que se profese al amigo, al amante, al confidente, no debe, en modo alguno, ser motivo para revelarle datos respecto al trabajo clandestino, porque al hacerlo se coloca en peligro a la persona y a la organización ${ }^{39}$.

La "reserva" tiene como función evitar la revelación de la pertenencia política clandestina que tiene el miliciano y la información que este tiene sobre las labores en curso. Por ende, la clandestinidad es descrita como "la única forma" de preservar la existencia de redes urbanas; dicha clandestinidad, entonces, exige asumir un "compromiso revolucionario" para mejorar -según el documento- "nuestra formación política-militar y [...] nuestra disciplina" 40 .

En segundo lugar, la compartimentación se basa en fragmentar la información para garantizar que "un golpe del enemigo" haga un daño "parcial" y no "total" a la organización: "cada uno debe saber únicamente lo necesario para su trabajo". Para que este proceso sea llevado a cabo habría tres requisitos: primero, la absoluta confianza en la dirección político-militar; segundo, la claridad en el aporte individual a la revolución; y tercero, la precisión en la planificación y el control de las tareas ${ }^{41}$.

El tercer y último fundamento del trabajo clandestino es la verticalidad; esto es, el respeto estricto de la jerarquización "de arriba hacia abajo y viceversa" de la organización y la aplicación de los principios leninistas del "centralismo democrático". Al respecto, las últimas líneas del documento problematizan y ponen en cuestión cualquier posibilidad de discrepancia frente a las labores que ordenan los altos mandos. Al final de los Principios de trabajo... se puede leer lo siguiente:

La existencia de la Democracia Interna [...] permite la discusión seria y responsable de los distintos aspectos políticos y militares en los marcos de la estructura clandestina. [...] Lo que ocurre es que éste (centralismo), o aquella (democracia) se fortalece o se reduce de acuerdo al carácter específico de las tareas o a la confrontación que tome la lucha de clases. En el marco de la legalidad la democracia prima sobre el centralismo, mientras en lo militar $y$ mucho más en lo clandestino, el centralismo se hace más férreo y la democracia se estrecha, para permitir la realización de los planes que se concretan a través de las órdenes. DE NUESTRA DISCIPLINA DEPENDEN MUCHAS VIDAS Y EL AVANCE DEL PROCESO REVOLUCIONARIO ${ }^{42}$

38 FARC-EP, Principios de trabajo clandestino, 1999[-2001], 1.

${ }^{39}$ Idem.

40 Ibid., 2.

41 En estos Principios de trabajo clandestino se agrega, entre comillas y sin referirse a autor alguno, lo siguiente: "«Nuestra organización se compone de combatientes, pero no de cualquier tipo de combatientes, sino de hombres que conscientemente han comprendido que su misión histórica es la de transformar nuestro país y que escogen la lucha armada, no solo como una forma de lucha revolucionaria, sino como la forma más elevada de la acción del pueblo contra sus enemigos de clase»: Ibid., 3.

42 Ibid., 4 - las mayúsculas son del original. 
De esta manera queda en evidencia que, de manera similar a la guerrilla rural, en las organizaciones clandestinas de origen fariano los pilares de su accionar eran la disciplina y el respeto a la verticalidad de mando. Esta rigidez del sistema jerárquico ocluyó el cuestionamiento a las tareas encomendadas por la cúpula guerrillera; esto podía, en efecto, ser entendido como indisciplina y peligro para la agrupación clandestina misma. De lo anterior se puede inferir que, en el proceso revolucionario impulsado por parte de las organizaciones milicianas de las FARC, la unidad y la homogeneidad interna primaban sobre la opinión o creencia que pudiera tener cada miliciano. Así, el mandato leninista del "centralismo democrático" promulgado por la agrupación fariana era puesto en cuestión por las premisas organizativas de la misma: al ser expresada la disciplina como derrotero imprescindible, la inclinación por el polo centralista de la consigna de Lenin -en detrimento del polo democrático- parecía revelar una tendencia irresistible hacia la rigidez militar y paratáctica de la guerrilla. Esta cuestión, sin duda, iba en detrimento de las reivindicaciones y propuestas netamente políticas de las FARC.

\section{Conclusiones}

Para 1997, un miembro importante de la cúpula de mando de las FARC condenó los mencionados fusilamientos internos de alias Javier Delgado en la llamada "Masacre Tacueyó". En el documento Habrá insurrección de masas (1997), escrito por el reconocido comandante del Bloque Oriental fariano Jorge Briceño Suárez -alias "Mono Jojoy"-, se puede leer lo siguiente: “[...] el drama de Tacueyó -en el que la dirigencia del disidente frente 'Ricardo Franco', con razón o sin ella, prácticamente acabó fusilando a toda su militancia-, ha sido la mayor derrota política y militar que ha sufrido la guerrilla en Colombia: la pérdida de absoluta credibilidad" 43 Este rechazo, es cierto, nos indica que establecer un vínculo automático entre la rigidez militar y una violencia ejercida al interior de las organizaciones de izquierda alzadas en armas puede resultar un ejercicio problemático debido a que dicha violencia es frecuentemente condenada por los mismos actores revolucionario. No obstante, llevada al extremo como en el caso de la "Masacre de Tacueyó", la preocupación por la delación parece haber sido el motivo principal de diferencias y problemas al interior de muchas de las organizaciones político militares de izquierda ${ }^{44}$.

En lo que respecta a las FARC, el establecimiento de un límite infranqueable entre un "nosotros" guerrillero y un "ellos" (el anti-pueblo), tan propio de las identidades populares totales -en las que podemos incluir otras organizaciones político-militares de izquierda latinoamericanas ${ }^{45}$, , revela que su rigidez identitaria precisaba de elementos que exacerbaran el orden al interior de sus filas. Así, factores como la disciplina y las dimensiones del trabajo clandestino sirven como medidas para evitar cualquier porosidad del límite establecido con la alteridad, cuya lógica puntual es la de erradicarla físicamente.

Según el investigador Medina Gallego, "[e]n general, excluyendo los mandos altos, la formación política y académica del militante promedio [de las FARC] es precaria y el discurso político se reduce a

43 FARC-EP, Habrá insurrección, 1997, 9 - el resaltado es nuestro. Posteriormente, algunos relatos periodísticos de los fusilamientos del Frente "Ricardo Franco" le valieron a alias Javier Delgado el apodo del "Monstruo de los Andes".

44 Este problema, es cierto, sigue suscitando debates al interior de las ciencias sociales colombianas y de la región En Argentina, por ejemplo, la relectura del papel de las organizaciones guerrilleras en los ajusticiamientos internos -el fusilamiento entre militantes, puntualmente- generó una discusión intelectual sin precedentes acerca del uso de la violencia por parte de la izquierda armada de los años sesenta y setenta del siglo XX. Gran parte de esta discusión quedó plasmada en la obra de Oscar del Barco et. al., No matar: sobre la responsabilidad, Córdoba, UNC-El Cíclope, 2007.

45 Como es el caso de Montoneros y del Partido Revolucionario de los Trabajadores-Ejército Revolucionario del Pueblo (PRTERP). Sobre este último ver el trabajo de Marco Iazzetta, "Lucha armada y política entre los años 1970-1976 en Argentina: la violencia ejercida por el PRT-ERP hacia el interior de su organización en su camino para conquistar el poder del Estado", Revista Pilquen Sección Ciencias Sociales 18, Viedma, 2015, 11-20. 
su mínima expresión" ${ }^{46}$. El autor considera, pues, que al interior de la organización fariana el ordenamiento militar sobresale en detrimento del reclutamiento político. La disciplina sería, entonces, "férrea" pero dudosamente "consciente". En otras palabras: la verticalidad guerrillera iría en detrimento del engagement político fundamental para toda agrupación guerrillera moderna. Si bien reconocemos que las conclusiones de Medina Gallego son argumentativamente tentadoras, creemos, empero, que pierden de vista el principio de escisión fundacional de las FARC en su enfrentamiento irrestricto contra el orden político vigente en Colombia. Para decirlo sin ambages: la importancia de las normas y reglamentos estrictos, de posibles castigos y "ajusticiamientos" ejemplarizantes, se correlacionan con una pretensión de homogeneidad y orden interno funcionales a la rigidez de la frontera política establecida por la organización guerrillera en su renunciamiento a la construcción hegemónica de la política. Creemos, a su vez, que la clandestinidad rigidizó aún más dicha frontera identitaria, lo que convirtió a las FARC-EP -tomando la tipología de Pizarro Leongómez expuesta en este trabajo- en una guerrilla de partido clandestino, esto es, una organización de partido cuya organización bélica es tan vertical e intransigente que pone en cuestión muchos de sus presupuestos políticos ${ }^{47}$.

Finalmente, consideramos que es una tarea todavía pendiente analizar el rol de la disciplina interna en el reciente proceso de paz entre las FARC y el gobierno de Santos. Esperamos que indagaciones subsiguientes logren auscultar la importancia de la verticalidad político-militar de dicha agrupación no sólo como estrategia para hacer la guerra sino también para alentar la desmovilización y la firma de los Acuerdos de paz de la Habana. De todas maneras, en este trabajo quisimos brindar pistas para entender el papel de la disciplina en la propuesta identitaria de las FARC; pistas, a nuestro parecer, bastante importantes para entender la particular forma en las que se han conformado las identidades políticas en Colombia durante la segunda mitad del siglo XX.

\section{Bibliografía}

Aboy Carlés, Gerardo, "De lo popular a lo populista o el incierto devenir de la plebs", Gerardo Aboy Carlés, Sebastián Barros y Julián Melo (coord.), Las brechas del pueblo. Reflexiones sobre identidades populares y populismo, Los Polvorines, UNDAV Ediciones, 2013, 17-40.

Aboy Carlés, Gerardo. Las dos fronteras de la democracia argentina: la reformulación de las identidades politicas de Alfonsin a Menem, Rosario, Homo Sapiens

Aguilera, Mario, Guerrilla y población civil. Trayectoria de las FARC 1949-2013, Bogotá, Centro Nacional de Memoria Histórica, 2014.

Arango, Carlos, FARC veinte años: de Marquetalia a La Uribe, Bogotá, Ediciones la Aurora, 47.

Beltrán, Santos Alonso, "FARC-EP: una reflexión sobre su organización política y militar", Carlos Medina Gallego (Coord.), FARC-EP. Temas y problemas nacionales, 1958-2008, Universidad Nacional-UNIJUS, 2008, $72-101$.

Del Barco, Oscar et. al., No matar: sobre la responsabilidad, Córdoba, UNC-El Cíclope, 2007.

Guzmán Campos, German, Orlando Fals Borda y Eduardo Umaña Luna, La violencia en Colombia: estudio de un proceso social, Bogotá, Ediciones Tercer Mundo, 1962.

Hilb, Claudia, Usos del pasado. Qué hacemos hoy con los setenta, Buenos Aires, Siglo XXI, 2013.

46 Medina Gallego, op. cit., 294.

${ }^{47}$ Queda para trabajos posteriores desarrollar a cabalidad esta hipótesis. 
Iazzetta, Marco, "Lucha armada y política entre los años 1970-1976 en Argentina: la violencia ejercida por el PRT-ERP hacia el interior de su organización en su camino para conquistar el poder del Estado", Revista Pilquen Sección Ciencias Sociales 18, Viedma, 2015, 11-20.

Jorge Giraldo Ramírez, Las ideas de la guerra. Justificación y crítica en la Colombia contemporánea, Bogotá, Debate, 2015.

Laclau, Ernesto y Chantal Mouffe, Hegemonia y estrategia socialista, Buenos Aires, FCE.

López Hernández, Claudia, ;Adiós a las FARC! ¿Y abora qué?, Bogotá, Penguin Random House, 2016.

Medina Gallego, Carlos, FARC-EP: Flujos y reflujos. La guerra en las regiones, Bogotá, Universidad Nacional de Colombia-UNIJUS, 2011.

Oquist, Paul, Violencia, conflicto y politica en Colombia, Bogotá, Instituto de estudios colombianos-Biblioteca Banco Popular, 1978.

Pécaut, Daniel, "Una lucha armada al servicio del statu quo social y político", Informe para la Comisión Histórica del Conflicto y sus Victimas, La Habana, 2015. La versión digital de este documento se puede encontrar en: https://www.ambitojuridico.com/BancoMedios/Documentos\%20PDF/una-lucha-armada-al-servicio-delstatu-quo-social-y-politico-1447170837-1460380657.pdf [Revisado el 10 de diciembre de 2018]

Pécaut, Daniel, Orden y violencia: evolución socio-política de Colombia entre 1930 y 1953, Bogotá, Editorial Norma, 2001.

Pizarro Leongómez, Eduardo, Insurgencia sin revolución. La guerrilla en Colombia en una perspectiva comparada, Bogotá, Tercer Mundo-IEPRI, 1996.

Rettberg, Angelika (comp.), Construcción de paz, en Colombia, Bogotá, Ediciones Uniandes, 2013.

Sánchez, Gonzalo y Ricardo Peñaranda (comp.), Pasado y presente de la Violencia en Colombia, Bogotá, Fondo Editorial CEREC, 1986.

Schmitt, Carl, Teoría del partisano. Acotación al concepto de lo político, Buenos Aires, Struhardt \& Cía., 2005.

Slipak, Daniela y Sebastián Giménez, "Pueblo, revolución y violencia. Las reactualizaciones revolucionarias del populismo", Estudios Políticos 43, México D.F., enero-abril 2018, 83-110.

Slipak, Daniela, Las revistas montoneras, Buenos Aires, Siglo XXI, 2015.

\section{Fuentes primarias}

FARC-EP, Estatuto, reglamento y normas de las milicias bolivarianas, 1989.

FARC-EP, Habrá insurrección, 1997.

FARC-EP, Principios de trabajo clandestino, 1999[-2001].

FARC-EP, Octava Conferencia Guerrillera, 1993. En línea: http://www.farc-ep.co/octava-conferencia/quees-la-conferencia-nacional-de-guerrilleros.html [consultado el 10 de diciembre de 2018] 